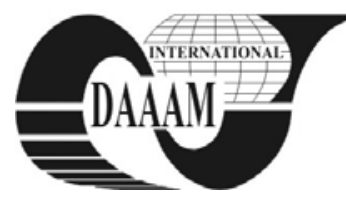

\title{
PREDICTIVE CONTROL OF NONLINEAR SERVO SYSTEM WITH DISTURBANCE REJECTION
}

\author{
PIKNER, M[ichal] \& KUBALCIK, M[arek]
}

\begin{abstract}
This paper is focused on a design of a control algorithm for a nonlinear servo system with disturbance rejection using predictive control strategy. The control algorithm was realized as a General Predictive Controller with constraints of input variables and for rejection of the measurable disturbance. The designed controller was applied to a laboratory servo system Amira DR300 in real-time conditions.
\end{abstract}

Key words: GPC, constrains, measurable disturbance, CARIMA model, laboratory model AMIRA DR300

\section{INTRODUCTION}

The servo system is typical equipment which is characterized by nonlinear behavior. This system can be successfully controlled by Generalized Predictive Control (GPC). Using this control strategy it is easy to ensure rejection of measurable disturbances.

\section{PREDICTIVE CONTROL}

The term Model Predictive Control presents a class of control methods which have common particular attributes (Camacho \& Bordons, 2004; Mikleš \& Fikar, 2007; Bobál et al., 2009; Bobál, 2009; Rossiter, 2003;):

- Mathematical model of a systems control is used for prediction of future control of a system output.

- The input reference trajectory in the future is known.

- A computation of the future control sequence includes minimization of an appropriate objective function (usually quadratic one) with the future trajectories of kontrol increments and control errors.

- Only the first element of the control sequence is applied and the whole procedure of the objective fiction minimization is repeated in the next sampling period. The principle of Model Based Predictive Control (MBPC) is shown in Fig. 1, where is the manipulated variable, is the process output and is the reference signal, and are called minimum, maximum and control horizont. This principle is presented in Fig. 1.

\subsection{Generalized Predictive Control}

The output predictions of the Generalized Predictive Controller are based on using a CARIMA model:

$$
A\left(z^{-1}\right) y(t)=B\left(z^{-1}\right) z^{-d} u(t-1)+C\left(z^{-1}\right) \frac{e(t)}{\Delta}
$$

Where the unmeasurable disturbance is given by a white noise coloured by $C\left(z^{-1}\right)$.

GPC uses a quadratic cost function of the form:

$$
J\left(N_{1} N_{2} N_{u}\right)=\sum_{j=N_{1}}^{N_{2}} \delta(j)[\hat{y}(t+j \mid t)-w(t+j)]^{2}+
$$

$$
+\sum_{j=N_{1}}^{N_{2}} \lambda(j)[\Delta \mathrm{u}(\mathrm{t}+\mathrm{j}-1)]
$$

Prediction can be written as

$$
\hat{y}=G u+f
$$

where $G$ is the matrix of the step response and $f$ is the free response.

Control algorithm has the form:

$$
\begin{gathered}
u=\left(G^{T} G+\lambda I\right)^{-1} G^{T}(w-f) \\
\Delta u=K(w-f)
\end{gathered}
$$

where $\mathrm{K}$ is first row of matrix $\left(G^{T} G+\lambda I\right)^{-1} G^{T}$.

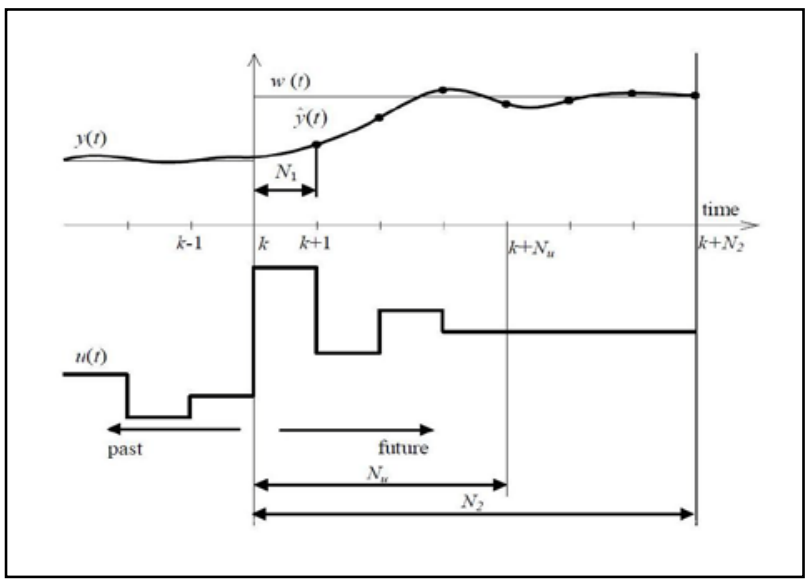

Fig. 1. The basic principle of the predictive control

\subsection{Measurable Disturbances}

Many processes are affected by external disturbances caused by the variation of variables that can be measured. Known disturbances can be taken explicitly into account in predictive control. In this case the CARIMA model must be changed to include the disturbances

$$
A\left(z^{-1}\right) y(t)=B\left(z^{-1}\right) u(k)+D\left(z^{-1}\right) v(k)+C\left(z^{-1}\right) \frac{e(t)}{\Delta}(6)
$$

where $v(k)$ is a $n \times 1$ vector of measured disturbances and $D\left(z^{-1}\right)$ is a polynom defined as

$$
D\left(z^{-1}\right)=d_{1} z^{-1}+d_{2} z^{-2}
$$

The resulting prediction equation is in the following form

$$
y(k+j)=G_{j}\left(z^{-1}\right) \Delta u(k+j)+L_{j}\left(z^{-1}\right) \Delta v(k+j)+y_{0 j}
$$


where

$$
\begin{gathered}
y_{0 j}=G_{j p}\left(z^{-1}\right) \Delta u(k-1)+L_{j p}\left(z^{-1}\right) \Delta v(k-1) \\
+F_{j}\left(z^{-1}\right) y(k)
\end{gathered}
$$

The predictions can be written in a compact vector form as

$$
\hat{y}=G \Delta u+L \Delta v+y_{0}
$$

\subsection{Constrained Model Predictive Control}

General formulation of predictive control with constraints is as follows

$$
\min _{\Delta u} 2 g^{T} \Delta u+\Delta u^{T} H \Delta u
$$

owing to

$$
A \Delta u \leq b
$$

\section{DESCRIPTION OF LABORATORY MODEL}

Laboratory model Amira DR300 (see Fig. 1) contains the technical realization of a nonlinear single-input/single-output system consisting of drive motor (M1), identical motor (M2) (used as current generator), tachogenerator $(\mathrm{T})$, incremental encoder (I) and clutch (K). A block scheme of the Amira DR300 is presented in Fig. 2.

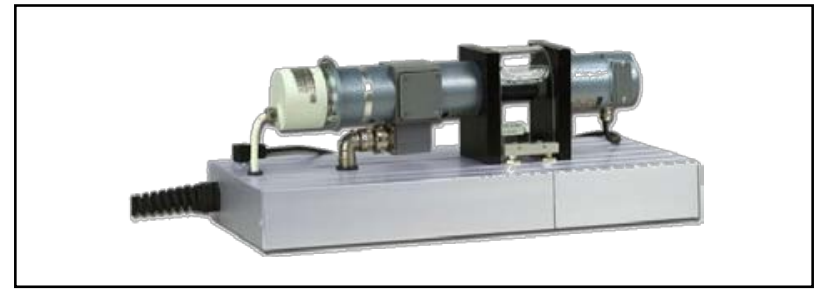

Fig. 2. Laboratory model Amira DR300

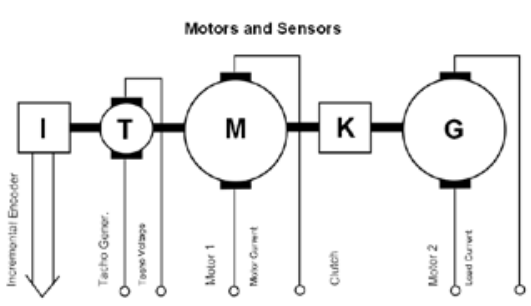

Fig. 3. Block scheme of Amira DR300

\section{EXPERIMENTAL RESULTS}

The Amira DR300 is a non-linear system. Its non-linear static characteristic is shown in Fig. 4. The initial parametres of recursive identification were determined from the transfer function (13). This transfer function was determined from linear part of the static characteristic.

$$
G(z)=\frac{B\left(z^{-1}\right)}{A\left(z^{-1}\right)}=\frac{0.2517 z^{-1}-0.022 z^{-2}}{1-0.9293 z^{-1}+0.147 z^{-2}}
$$

Sample time period $T_{0}=0.05 \mathrm{~s}$ was used for identification and control of system.

A sinusoidal signal was used as a measurable disturbance. The amplitude of the signal was $0.2 \mathrm{~V}$. Weighting factor $\lambda$ was set to 5. Minimum, maximum and control horizonts of predictive control were $N_{1}=1, N_{2}=5, N_{u}=3$. Results of predictive control with rejection of the measurable disturbance are in (Fig. 5).

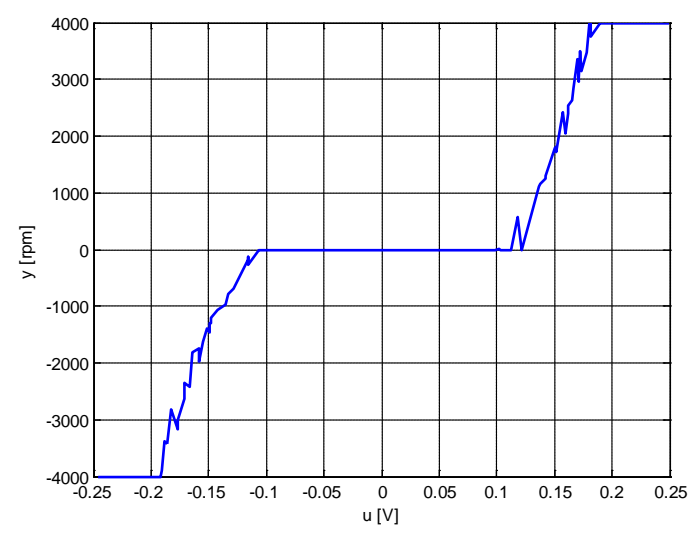

Fig. 4. Non-linear static characteristic
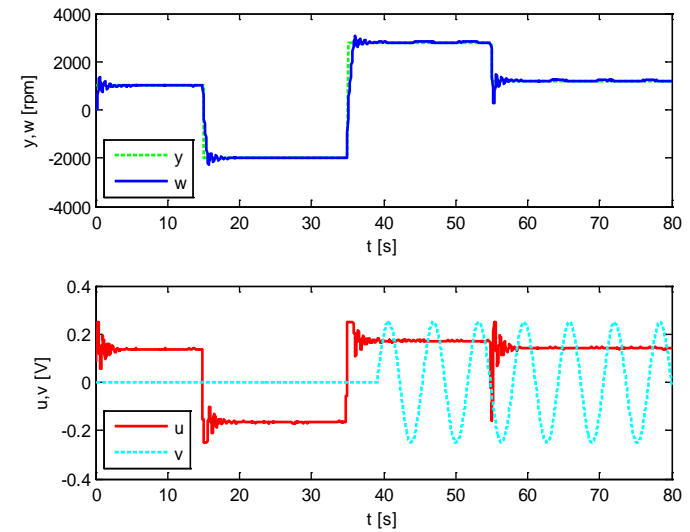

Fig. 5. Control with compensation of measurable disturbance

\section{CONCLUSION}

The control tests executed on the laboratory model gave satisfactory results. The objective laboratory model simulates a process, which frequently occur in industry. Computation of prediction equation was extended by considering measurable disturbance. It was proved that the examined method could be implemented and used successfully to control such processes.

\section{ACKNOWLEDGEMENTS}

This work was supported in Tomas Bata University in Zlin under grant IGA/34/FAI/11/D.

\section{REFERENCES}

Balate, J. (2003). Automticke rizeni, 1. release, BEN, 80-7300020-2,Prague

Bobál, V. (2008). Adaptive and Predictive control, Tomas Bata University in Zlín, Academia centre, 978-807318-662-3, Zlín (in Czech)

Camacho, E. F. \& Bordons, C. (2004). Model Predictive Control, Springer-Verlag, 978-1-85233-694-3, London

Corriou, J. P. (2004). Process control Theory and Applications, 1. Release, London: Springer-Verlag, 1-85233-776-1, London

Rossiter, J. A. (2003). Model-Based Predictive Control A Practical approach,CRC Press, 0-8493-1291-4,USA 